\title{
Application of Whole Membrane Water Treatment Technology in Environmental Protection
}

\author{
Cuiyan Wang \\ Jilin City Ecological Environment Bureau, Jilin City 132001, Jilin Province, China
}

\begin{abstract}
In the current social development of our country, environmental protection has become a key content, and water treatment process is a key step to achieve environmental protection. This paper analyzes the application of whole membrane water treatment technology in environmental protection. It is hoped that this analysis can be helpful for the rational application of the whole membrane water treatment technology and the improvement of environmental protection quality.

Key words: Environmental protection; Water treatment process; Whole membrane water treatment technology; Technology
\end{abstract}

Publication date: September, 2020

Publication online: 30 September, 2020

*Corresponding author: Cuiyan Wang, 719296815@ qq.com

\section{Introduction}

With the rapid development of industrialization, environmental problems have been paid more and more attention, especially in water environment protection. The whole membrane water treatment process is an advanced and effective water treatment technology. The application of this technology to water treatment has a very far-reaching significance for people's water safety and environmental protection. Therefore, in today's environmental protection, we should strengthen the application and research of the whole membrane water treatment technology, to give full play to its technical advantages, so as to improve the environmental protection effect.

\section{Brief introduction of whole membrane water treatment process}

\subsection{Ultrafiltration}

Ultrafiltration is also known as UF. This membrane separation technology mainly uses pressure as the driving force to realize the separation of macromolecules and small molecules. In the specific application of this technology, a membrane with pore size of $1.5 \mathrm{~nm}-2.0$ $\mu \mathrm{m}$ is usually used for filtration, and the liquid pressure difference is used as the power of filtration, and the separation effect is achieved by the screening effect of membrane pore ${ }^{[1]}$. The main advantages of this method are high filling density per unit container and small floor area.

\subsection{Counter-infiltration system}

Reverse osmosis system, also known as RO, mainly realizes the removal of organic matter, ions, impurities and suspended solids in water through the application of osmosis principle. When the pressure is constant, the filter membrane will enter water or dissolve, and the two sides of the filter membrane can be divided into two parts, one part will realize the membrane purification of water through reverse osmosis, the other part is the residence and concentration place of various solid residues and salt.

\subsection{EDI system}

EDI system is the abbreviation of electrode ionization. It is a new treatment process of desalting by electrodialysis and ion exchange. The basic structure of EDI system is electrodialysis device. The strong acid cation exchange resin and strong alkali anion exchange resin are filled between the positive and negative membranes, to form a mixed bed between the positive and negative membranes, to improve the desalination speed It needs to consume acid and alkali to regenerate automatically. This technology is also known as continuous electric desalting technology because it can 
keep water flowing continuously.

\section{Application of whole membrane water treatment process in environmental protection}

\subsection{Application of ultrafiltration process}

When the external pressure is constant, the solution to be separated will flow at a certain speed on the surface of one side of the ultrafiltration membrane. At this time, colloidal particles, macromolecular substances, microorganisms, bacteria and pyrogen can not pass through the membrane, so they will be gradually concentrated on the membrane surface and in the drainage solution, and then discharged with the help of concentrated water and backwashing process. The particle size ratio is more than $100 \%$. The small pore size of the membrane and soluble substances will pass through the membrane pore and reach the other side to form product water, to achieve the separation and purification effect. In fact, ultrafiltration is a treatment process in the form of sieve pore separation, mainly including internal pressure separation and external pressure separation. With the help of ultrafiltration process, many impurities such as colloid, suspended solids, bacteria, organic macromolecules and microorganisms can be removed, and the filtration performance is very good. Compared with the traditional multi-media filter + chemical dosing + activated carbon filter treatment, the process can further reduce the pollution index SDI, so as to improve the water quality, and the whole process can be automatically controlled. The impurity removal rate is as follows.

Table 1. Impurity removal rate of ultrafiltration process

\begin{tabular}{ccc}
\hline $\begin{array}{c}\text { Serial } \\
\text { number }\end{array}$ & Impurity & Removal rate \\
\hline 1 & Colloidal iron & $99 \%$ \\
2 & Percoll & $99 \%$ \\
3 & Suspended matter & $100 \%$ \\
4 & Colloidal aluminum & $99 \%$ \\
5 & SDI & $<3.0$ \\
6 & Microorganism & $99.999 \%$ \\
7 & Total organic carbon TOC & $\approx 30 \%$ \\
\hline
\end{tabular}

\subsection{Application of reverse osmosis system}

Reverse osmosis system is very suitable for the removal of particulate impurities, and can also remove organic matter with a certain molecular weight, and has a relatively high removal rate. In addition, as an ionexchange desalination system, reverse osmosis system can significantly extend the regeneration cycle of ion exchange resin, so as to significantly reduce acid and alkali consumption ${ }^{[3]}$.

In the whole membrane water treatment process, this technology is the most precise separation technology. For organic matter with molecular weight above 100 and all dissolved organic matter, reverse osmosis technology can play an effective blocking role, but water molecules can pass through it. Reverse osmosis (RO) membrane is a kind of thin film made of special materials and special methods. It has semi permeability. Some components in aqueous solution can be selectively permeated by external pressure to achieve purification, concentration or desalination. The following are the main process parameters of reverse osmosis system.

Table 2. Main process parameters of reverse osmosis system

\begin{tabular}{ccc}
\hline $\begin{array}{c}\text { Serial } \\
\text { number }\end{array}$ & Project & Parameter \\
\hline 1 & $\begin{array}{c}\text { Minimum particle size for } \\
\text { impurity removal } \\
\text { Desalination rate } \\
2\end{array}$ & $\approx 0.0001 \mu \mathrm{m}$ \\
3 & $\begin{array}{c}\text { Minimum molecular } \\
\text { weight of organic matter } \\
\text { that can be removed } \\
\text { Desalination rate } \\
\text { of cellulose acetate } \\
\text { membrane }\end{array}$ & $>95 \%$ \\
4 & $\begin{array}{c}\text { Desalination rate of } \\
\text { reverse osmosis composite } \\
\text { membrane }\end{array}$ & $>95 \%$ \\
\hline
\end{tabular}

Because the application of reverse osmosis system does not need much high operating costs, and the environmental benefits are very high, these environmental problems such as renewable acid-base pollution can be basically solved. Therefore, in today's many industrial production make-up water, circulating water and waste water recovery, the technology has been widely used. Especially in the make-up water of power plant boiler, this technology has played a significant advantage, which can effectively solve the problem of waste acid and alkali discharge, and achieve good environmental protection effect on the basis of meeting the production demand and ensuring the production benefit.

\subsection{Application of EDI system}

EDI water treatment technology is a kind of technology based on electrodialysis technology. High purity water is produced by combining selective membrane and ion exchange resin packed bed. In EDI system, the most common equipment is the equipment that many modules are assembled in parallel. In this equipment, the water yield of each module is fixed, usually several tons per hour. Because the resin can be continuously regenerated, this treatment process can also be carried 
out continuously. In the process of water treatment by this process, the plate and frame module is the most common. In the specific application, because EDI components have higher requirements for the quality of influent water, in order to ensure the good operation of the system, two-stage osmosis membrane can be added or softener can be set.

Ion exchange membrane and ion exchange resin have very similar working principle, which can realize the selective passing of ions. The following is the schematic diagram of EDI system(Figure 1). The left side is the positive electrode, and the measurement is the negative electrode. The ion passing process is polar water concentrated water polar water.

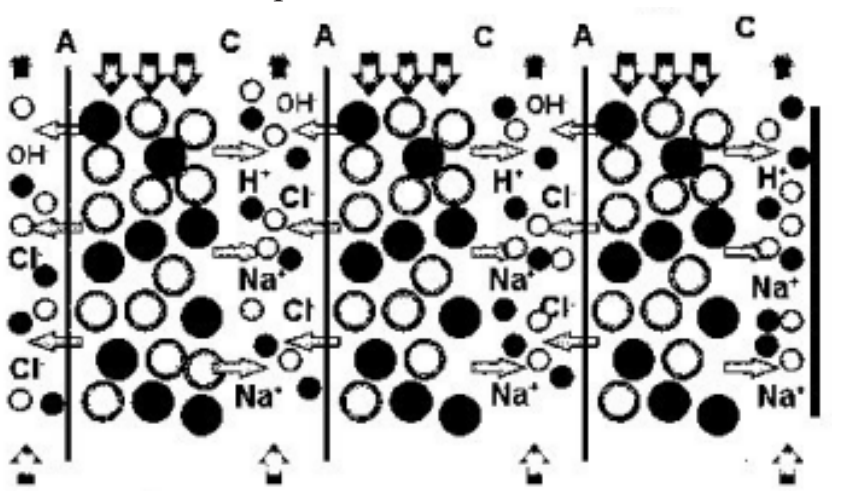

Figure 1. Schematic diagram of EDI system

As shown in figure 1, anions can only pass through the anion exchange membrane, but not from the cation exchange membrane; Cations can only pass through the cation exchange membrane, but not from the anion exchange membrane. When the mixed ion exchange resin is filled between each pair of anion exchange membrane, an EDI unit can be formed. The space occupied by the resin is called fresh water chamber. A certain number of EDI units are listed together, so that the anion and cation exchange membranes are arranged alternately, and some ion exchange resins with special properties are added between the ion exchange membranes. The space formed is called the concentrated water chamber. With a given DC voltage, the anion in the ion exchange resin in the fresh water chamber will shift towards the positive electrode, and the cation will shift towards the negative electrode. Then, it will pass through the anion and cation exchange membrane and enter the concentrated water chamber. The ion exchange resin will adsorb the ions in the water supply, so the vacancy left by the ion electromigration will also stand up. The carving is occupied ${ }^{[4]}$. In essence, ion migration and ion adsorption usually occur at the same time and have continuity. Therefore, through this treatment process, ions in the feed water will continuously pass through the ion exchange membrane, and then enter the concentrated water chamber. After ion removal in the concentrated water chamber, the desalted water will be obtained.

\section{Conclusion}

To sum up, in today's environmental protection, water resources protection is a key content. The whole membrane water treatment technology is a key technology in water environment treatment. Therefore, in order to achieve good water resources protection effect and improve the quality of environmental protection, the whole membrane water treatment technology should be reasonably applied, and the effective treatment of water resources should be carried out through the reasonable application of ultrafiltration treatment process, reverse osmosis treatment system and EDI treatment system. At the same time, we should strengthen the research on the whole membrane water treatment technology, and constantly improve the process performance, so as to comprehensively improve the water purification degree, meet the water demand of today's society, and realize the sustainable development of resources and environment.

\section{References}

[1] Zhang YN, Jia WK. Application of whole membrane water treatment technology in environmental protection[J]. Building engineering technology and design, 2020 (21): 68.

[2] Zhang XC. Application of whole membrane water treatment technology in environmental protection $[\mathrm{J}]$. Science and technology perspective, 2020 (11): 217-219.

[3] Zhang QR, Gao HC, Sun ZF. Application of whole membrane water treatment technology in environmental protection[J]. Chemical industry management, 2020(9): 69-70.

[4] Dong JJ. Practice of full-membrane water Treatment Technology in environmental Protection[J]. China's Comprehensive Utilization of Resources, 2019(8): 21-23. 